\title{
Training Need Analysis at Manas Agro Industries and Infrastructure Ltd.

\author{
${ }^{* 1}$ Dr. Kanak Wadhwani, ${ }^{2}$ Ms. Alpana Deshpande \\ ${ }^{1}$ Assistant Professor, Shri Ramdeobaba College of Engineering and Management, Nagpur \\ ${ }^{2}$ Vice President - Human Resource, Manas Agro Industries and Infrastructure Ltd. \\ Email: wadhwanik@rknec.edu
}

\section{Received: $20^{\text {th }}$ September 2018, Accepted: $11^{\text {th }}$ October 2018, Published: $31^{\text {st }}$ October 2018}

\begin{abstract}
The research work was undertaken with the objective to understand the working Systems at Unit II of Manas Agro Industries and Infrastructure Ltd. situated at Village Kolari. The research involved the conduction of Job Analysis of the various positions at the plant and to understand the deployment of manpower at each level. Further, the paper focuses on the working environment and culture at Unit II.

Based on interviews Training needs of employees at Manas were identified. Paper aims suggesting relevant areas of training for employees in order to increase their efficiency at work.
\end{abstract}

\section{Keywords}

Job Analysis, Training Need Analysis, Manpower Deployment

\section{Introduction}

Company Profile

MAIIL; Manas Agro Industries and Infrastructure Limited, a Conglomerate is owned and managed by experienced group of professionals with high expertise in various industries. A diversified group consisting businesses of strategically crucial ventures such as Sugar Power and Distillery and LPG has a huge business growth. MAIIL has a strategic partnership with ESSAR petroleum for supply of Ethanol blended petrol at affordable rates

The research paper depicts Training need Analysis conducted at Unit II of MAIIL. The study was undertaken at MAIIL so as to understand the working Systems at Unit II situated at Village Kolari. Unit II is involved in generating Power and is regarded amongst the most efficient plants in Vidarbha. The power plant supply Nonconventional energy to the power-starved state of Maharashtra. They are utilizing rice husk/saw dust as the primary fuel for the Co-gen plant. Plant is operated 24 Hours \& employees work in 3 different shifts.

\section{Training Need Analysis}

Training need Analysis (TNA) is used to assess organization's training needs. In this process a detailed examination of possessed skills and required Skills is done. The outcome is to identify the type of Training that can be identified $\&$ delivered to the employees for the mutual benefit to individual employee \& the organization. . The idea behind TNA is to channelize the efforts of providing training in a right direction. TNA can be done at Organization level, Task Level \& Individual Level, based on the type of organization and nature of job profiles.

\section{Materials and Methods \\ Research Objectives}

1. To identify training needs of employees at MAIIL.

2. To classify the types of skills required by the organization for the further development of its business.

3. To identify types of skills required to equip employees to enhance their performance.

4. To suggest ways to improve the overall culture of the Organisation.

\section{Research Methodology \\ Methods Used}

The method used for the study was a structured interview. The questionnaire used for the study was discussed with the HR Department of MAIIL. Inputs given by HR Department were incorporated in the final Questionnaire. The study was undertaken in different intervals. In the initial interaction with employees, overall Working Conditions \& various tasks undertaken were understood. While doing so representatives from all the Departments were involved $\&$ there was structured Interview. The employees were made aware about the purpose of the Interview in the beginning. Average time spent on interviewing the employee was 20 Minutes. Convenience Sampling was put to use by Researchers. 
After few days, researchers discussed with another set of employees who were representatives of all the department but were working in different shifts in the first interval. This intervention was carried out on the basis of the discussions held with HR Department to identify the grey areas where training is required. Observations made were based on qualitative data that was collected during the discussion with employees in different shifts.

\section{Research Tool (Questionnaire)}

For the purpose of the study, questionnaire was designed in consultation with HR Department. Open \& Close ended questions were incorporated to collect the data. The tool was used to identify Technical \& Behavioral Training.

\section{Universe}

The total number of employees employed at Unit II is 97 which is the universe for the current study. All the employees were working in various Departments viz. Electrical, Turbine, Boiler, DM, Maintenance, Fuel Unloading, CHP/AHP Section, Weigh Bridge, Administration, Time Office, Stores.

\section{Sample Size}

70 employees belonging to different departments were interviewed in different intervals. During first interval, employees contacted were $32 \& 3$ senior level executives including Plant In charge. In the second interval another set of employees contacted were 33 that were different from first interval \& 3 senior level executives including Plant In charge with focused discussion for identifying the Training Needs.

Based on the information obtained from Phase I, a questionnaire was structured considering the aspects of culture and behavior of employees at organization. Skills for which the employees shall be trained are discussed in the next section.

\section{Results and Discussion}

\section{Training Needs Identified}

Through questionnaire, Interviews with the employees, training needs for MAII are identified. The current research has identified various types of Training that needs to be imparted on the employees. Training types are classified under three heads viz. Technical, Soft Skills \& Behavioral with specific emphasis on the requirement of employees, department that they represent $\&$ the requirements of organization.

Technical Training
Needs
- Inventory
Management
- Basic Computer Skills
- SAP Training
- Workplace Technical
Safety
- Behavioral Based
Safety

\section{Soft Skills Training Needs}

- Change Management

- Effective Time Management

- Induction

- Written Communication

- Etiquettes
Behavioural Based

Training Needs

- Employer branding and Ownership

- Training program on Self Improvement

- Conflict Management

- Working in Teams

\section{Technical Training Needs}

1. Inventory Management: It was observed that the management of inventory was not done efficiently and hence the staff in the store need a training in how to manage inventory and store the Store in a more efficient manner. This sentiment was also expressed by the employees themselves.

2. Basic Computer Skills: All the employees in the Administration department, control room and store need to be trained in basic computer skills as they use them on a frequent basis.

3. SAP Training: All the employees in the departments that are using SAP need to be trained in SAP as work gets affected when the employee who is trained in SAP is on leave or is not on duty at the time the work comes up. 
4. Workplace Technical Safety: It is observed that certain employees are not entirely aware about the technical aspect of safety. This technical training along with Fire Safety Drills will impact the Safety behavior of the employees.

5. Behavioral Based Safety: Apart from technical training in safety training needs to be given to create a positive attitude of the employees towards safety and safety regulations.

\section{Soft Skills Training}

1. Change Management As the organization has undergone a major change in terms of the merger. It is recommended that the employees are given a training in how to manage this change and be more accustomed to it.

2. Effective Time Management In a bid to improve utilization of manpower and optimization of the workforce the employees will be given additional work and portfolios. As the employees are not accustomed to this it is recommended that they are given training in effective time management.

3. Induction As discussed earlier the employees are not aware about the Manas Group as a brand and another step in this would be a formal induction program being arranged for the employees showcasing the brand and also discussing various behavioral and cultural areas that the organization wants to focus on. The vision of the organization can also be shared here to improve the ownership levels of the employees.

4. Written Communication This training is especially for the employees who are interacting through e-mails and are generating various reports for the organization. A training in written communication is recommended to improve the overall communication of these employees.

5. Etiquettes As the employees are interacting with their peers from other units as well as the external environment such as vendors, government officials, third party consultants etc. it is recommended that they are given a training in corporate etiquettes.

\section{Behavioral Based Training Needs}

Employer branding and Ownership: Continuous efforts needs to be taken by organization to make the employees feel that they are part of one Big Family. They should be made aware of the people, philosophy \& value system of Manas Group.

Training program on Self Improvement:

Conflict Management: Employees must be made aware about the different facets of Conflict Management. Internal strife amongst the different department was quite evident. Employees must be trained to collaborate with each other. Working in Teams: As mentioned above, Team culture must be imbibed by the employees. Employees must not think in isolation rather they should support each other. Out bound Training can be organized for the employees to improve their coordination.

\section{General Observations during the Study}

\section{Safety}

a. A lax attitude towards personal safety has been observed. As no major accidents have happened yet they do not take safety seriously.

b. Safety shoes and helmets were provided however due to size issues were sent for exchange and have not been reissued.

c. Employees feel that safety helmets should be given individually and not shared among employees.

d. Employees feel that if the organization makes it compulsory and take disciplinary measures only then everyone will start wearing them.

e. The safety committee is not taken seriously and the work is kept pending for quite a few months now.

f. The higher officials do not seem to have taken the issue of safety as top priority. 2. Miscellaneous Observations

a. The employees are not aware of the overall operations of Manas as a Group. It is evident that ownership was missing in the employees.

b. Majority the employees have been working in the organization for over 6 to 7 years \& emotional about they are still thinking on the basis of the old organizational set-up.

c. They lack enthusiasm in terms of giving ideas and innovation as in the past their ideas were neither given any importance nor were they communicated so as to why their ideas may not be implemented in the organization. This has led them to believe that there is no point in giving suggestions.

d. The overall climate in terms of interpersonal relationships is strong and has been built over the years. However, this feeling of camaraderie has led to the employees looking at newer employees as outsiders and there is a lower level of trust in newer employees. 
e. There is a palpable tension between the Operations and Administration of the plant. This needs to be looked into as it may lead to issues in the future.

f. There generally seems to be a feeling of awe attached to people coming to the plant from the Head Office.

\section{Conclusion and Recommendations}

The following recommendations are being given to improve the performance of employees:

1. Skip Level Meetings: Regular formal meetings between officials from the Head Office with the workers should be conducted. This meeting can act as a bridge between plant and the $\mathrm{HO}$ and will improve Employee Ownership levels as the employees will feel that their ideas are being heard by the management. These meetings can also act as triggers for the employees to give direction to their efforts in line with the organizations vision.

2. Sensitization towards Brand: During the course of the study it was observed that the employees at the plant are not fully aware of the magnitude of activities that are undertaken by the organization. They are still confined to thinking of Manas as a small unit limited to their plant. This lack of understanding is also a cause for reduced ownership levels as they do not know the possibilities career growth and development in front of them. Conducting sessions of sensitization towards the brand of Manas through videos, seminars, inter unit visits and employer branding initiatives will help improve the same.

3. Inter Unit Visits: As discussed earlier the employees do not have knowledge of the activities undertaken by Manas Group. Another way of improving this would be by arranging Field Visits to other units of the group. Once the employees get information about the organization they work for there will be an improvement in the level of belongingness they feel in the organization. Further, the employees will also be able to understand the best practices employed by other plants and may employ the same at their workplace.

4.Inter Unit Competition: The organization can conduct work oriented Inter Unit Competitions such are awards for Cleanest Plant or Most Innovative Practices etc. This would improve the ownership that the employees have towards the work that they do and also towards their work place. The increased competitive spirit will encourage the employees to improve their productivity and efficiency.

Corporate Magazine Another method of increasing the affinity of employees towards the organization would be a periodically printed Corporate Magazine that publishes achievements of the employees (both personal and professional). This will act as a method of rewarding and recognizing the employee on a corporate level.

The following recommendations are being given to imbibe a positive attitude towards Safety:

Inter Unit Safety Audit: Inter Unit Safety Audits can be undertaken by employees. These Audits being Inter Unit will serve a dual purpose. First, the Units will get to understand Safety lacunas from the perspective of a third party. Second, the employees who are the Auditors will start practicing the safety behaviours that they are recommending to their peers.

Safety Orientation: It has been observed that the employees are not having an orientation towards personal safety has they are not realizing the potential hazards of their working environment. In cases where there is awareness there is a lax attitude towards safety. A Safety Orientation Training will help in aligning the employees to the organizational goal of providing a safe working space and improve safety behaviour.

Fire Safety Drills: Conducting regular Fire Safety Drills will ensure that the employees are prepared to deal with any fire emergencies that may arise in the future. Each individual employee will know the role they are supposed to play in such emergencies. Further, it will show that the organization is serious about safety.

Disciplinary Action for Safety: It was observed during the study that the employees did not have initiative in practicing Safety regulations in the plant premises. Thus, it is suggested that disciplinary measures such as making wearing of helmets, safety shoes etc. mandatory and taking corrective action such as sending the employee back from the gate itself etc. need to be practiced by the organization.

\section{References}

1) Authored by Aarti Chahal, International Journal of Business and Management Invention ISSN (Online): 2319 8028, ISSN (Print): 2319 801X, www.ijbmi.org Volume 2 Issue $4 \|$ April. 2013\| PP. 41-51, A Study of Training Need Analysis Based Training and Development: Effect of Training on Performance by Adopting Development Based Strategy.

2) Mohd. Anuar bin Arshad, Ahmad Nasir bin Mohamad Yusof, Mediterranean Journal of Social Sciences MCSER Publishing, Rome-Italy, Vol 6 No 4 S3 August 2015, titled A Study on Training Needs Analysis (TNA) Process among Manufacturing Companies Registered with Pembangunan Sumber Manusia Berhad (PSMB) at Bayan Lepas Area, Penang, Malaysia 